\title{
Optimal Design of Plate-Fin Heat Sink under Natural Convection Using a Particle Swarm Optimization Algorithm
}

\author{
C. H. Liang ${ }^{1,3^{*}}$, S. Zeng ${ }^{1}$, Z. X. Li $^{2}$, D. G. Yang ${ }^{1}$ and S. A. Sherif ${ }^{3}$ \\ ${ }^{*}$ School of Mechano-Electronic Engineering, Guilin University of Electronic Technology, \\ Guilin, 541004, China \\ ${ }^{2}$ Department of Environmental Engineering, Shan Xi University, Taiyuan, 030006, China \\ ${ }^{3}$ Department of Mechanical and Aerospace Engineering, University of Florida, Gainesville, \\ 32601, USA
}

Email: lianghang@guet.edu.cn

\begin{abstract}
The purpose of this study is to find the optimal designing parameters of a plate-fin heat sink under natural convection using the Particle Swarm Optimization (PSO) Algorithm. Minimization of entropy generation rate under given space restrictions is considered as objective functions. All relevant design parameters for plate-fin heat sinks are the fin height, fin number, fin thickness. The constraints of the variables are set according to the suggestion structure design. And this three variables influence on entropy generation are presented. In the present study, In order to prevent the size of the heat sink is too large, we use the penalty function method in this study. Then the code for the PSO is written in MATLAB. On this basis, the optimal size of heat sink was obtained through the particle swarm algorithm for numerical simulation of this model: fin height is $44.8 \mathrm{~mm}$, number of fins is 25 , fin thickness is $0.6 \mathrm{~mm}$ and base temperature is $342.6241 \mathrm{k}$.
\end{abstract}

Keywords: Pate-fin, Heat sink, Particle swarm optimization, Entropy generation, Optimization.

\section{INTRODUCTION}

Since the recent development in integrated circuit (IC) technology over the past few decades, electronics have become faster, smaller and more powerful, which leads to an ever-increasing heat generation rate from electronics devices. This trend inevitably leads to the increase of heat generation rate per volume of the electronics devices $[1,2]$. If the heat can not be removed timely, the components will accelerate the ageing. Even worse, it will affect the normal operation of the electronic device [3]. Therefore, thermal management becomes a fundamental but crucial element in electronic product design. Many cooling methods have been proposed to maintain the temperature of electronic components in safety zone [4-6], like thermoelectric cooling, air cooling and liquid cooling. Due to their inherent simplicity, operational safety and low long-term cost, natural convection heat sinks have been widely used in cooling electronic components. The factors that affect the performance of a heat sink are the thermal conduction resistance, choice of material, protrusion design and surface treatment. Also, heat sink attachment methods affect the die temperature of the electronic components. The massive parameters make the optimal design of the heat sinks a challenge.

There is an increasing interest among researchers in the development of heat sink processes for heat dissipation and many optimization process for heat sink design have been proposed. Many researchers [7-9] have conducted experiments to study the performance of heat sinks. For optimal design of heat sink, the method of entropy generation minimization introduced by Bejan [10,11], provides a procedure for simultaneously optimization of heat sink design parameters as they relate to not only viscous effects but also thermal performance. Using the entropy generation minimization technique, Culham and Muzychka [12] optimized a plate-fin heat sink equipped with a flow-through air inlet system. Further, by considering the geometry constraint effect on the performance of heat sink, Shih and Liu [13] concluded that the optimal designed heat sink process outperforms the conventional ones. Iyengar and BarCohen [14] presented a coefficient of performance analysis for plate fin heat sinks in forced convection. In their study, a viable technique was provided for combining least-material optimization with the entropy minimization methodology.

In order to improve the thermal performance of the heat sink about the CPU, Chen et al [15] apply a finite element method to investigate the heat transfer phenomena of a heat sink process firstly, then, a real coded genetic algorithm was applied to search for an optimal set of plate-fin parameters. The optimal geometry size of heat sink was obtained by Adewumi et al [16] using the computational fluid dynamics code with a goal-driven optimization algorithm. Waghmare et al [17] used the teaching-learning-based optimization algorithm for optimization of plate-fin heat sink equipped 
with flow-through and impingement-flow air cooling system. Height of fins, number of fins, spacing between two fins and oncoming air velocity are considered as the design variables. Finally, the author concluded that the plate-fin heat sink with flow-through air cooling system is better than the plate-fin heat sink with impingement-flow cooling system. Faraji et al [18] apply the TDMA algorithm to optimize the thermal performance of a phase change material heat sink and develop A mathematical model about it. The results show that the optimized heat sink has good performance. For the pin-fin heat sink, Chiang et al. [19] optimized the design parameters of Pin-Fin Heat Sink with multiple thermal characteristics using the grey-fuzzy logic based on the orthogonal arrays. In addition, the effect of the design parameters on the thermal performance characteristics of the heat sink was found using the analysis of variance (ANOVA).

However, there has been less research work on using Particle swarm optimization (PSO) for heat sink design. Since the particle swarm algorithm is put forward by Kennedy and Eberhart [20], the successful use of the Particle swarm optimization (PSO) for practical problems has been reported every year. The goal of this paper is to demonstrate the geometrical design of a plant-fin heat sink under natural convection by using PSO. The objective functions known as entropy generation rate with five constraints have been taken to measure the performance of the heat sink. Three optimization variables are fin number, fin height, fin thickness respectively. According to our design experience, we have found that an optimal design simply based on a lowest entropy generation rate often leads to a larger size of heat sink. So, in order to meet customer needs, the penalty function is used in this study to prevent the size of the heat sink is too large.

This paper is organized in the following manner. First, we present the object function in section 2 . The following section then briefly describes the particle swarm algorithm. In order to meet the size requirements of the heat sink, the constraint condition is given in section 4. Section 5 shows the flowchart of PSO algorithm. The next section is to analyze the results and verify the accuracy of the results. Finally, concluding remarks are given in Section 7.

\section{MATHEMATICAL MODEL}

For optimization, an overall maximum volume of $290 \mathrm{~mm}$ $\times 84 \mathrm{~mm} \times 75 \mathrm{~mm}$ heat sink model as shown in Figure 1 has been taken to optimize based on Particle Swarm Optimization Algorithm. We assumed that a total heat dissipation of 28.8 $\mathrm{W}$ is uniformly applied over the base plate of the heat sink. The thickness of the base plate of the heat sink, $t_{b}$, is $4 \mathrm{~mm}$. The thermal conductivity of the heat sink material, $\mathrm{K}_{\mathrm{a}}$, is set to be $200 \mathrm{w} / \mathrm{mk}$ and the ambient temperature around heat sink, $\mathrm{T}_{2}$, is set to be $303.15 \mathrm{k}$.

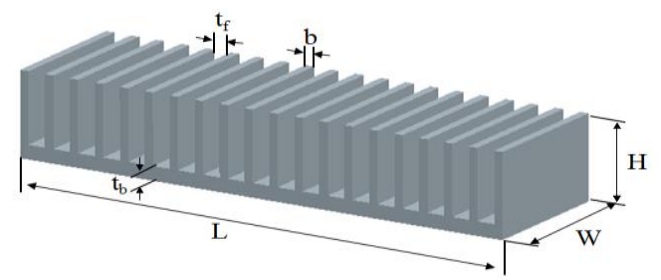

Figure 1. The geometric parameters of the plate fin heat sink
According to the methodology of Bejan [11], entropy generation rate $\left(\dot{S}_{g e n}\right)$ for extended surface under free convection is defined by the following relationship

$$
\dot{S}_{\text {gen }}=\frac{Q \theta_{\mathrm{b}}}{T_{2}^{2}}
$$

where $T_{2}$ is ambient temperature, $Q$, and $\theta_{\mathrm{b}}$ are total heat dissipated from heat sink and the temperature excess of the heat sink base plate respectively. The relationship between the temperature excess of the heat sink $\left(\theta_{\mathrm{b}}\right)$ and the overall heat sink resistance is defined as

$\theta_{\mathrm{b}}=Q R_{\text {sink }}$

Therefore, entropy generation rate is rewritten as

$\dot{S}_{\text {gen }}=\frac{Q^{2} R_{\text {sink }}}{T_{2}^{2}}$

The overall thermal resistance of the heat $\operatorname{sink}, R_{\text {sink }}$, is defined as

$R_{\text {sink }}=R_{\text {total }}+R_{\text {base }}$

$R_{\text {total }}$ is the total thermal resistance that is resulted from the fins and the exposed base plate and is given by

$R_{\mathrm{total}}=\frac{1}{\frac{n}{R_{\mathrm{fin}}}+h b L(n-1)}$

where $\mathrm{n}$ is fin number, $\mathrm{h}$ is heat transfer coefficient, $\mathrm{b}, \mathrm{L}$ are fin space and fin length respectively. And $R_{\text {fin }}$ is the thermal resistance of a single fin. It will be modeled using the solution for a straight fin with an adiabatic tip.

$R_{\text {sink }}=\frac{1}{\sqrt{h P K_{\mathrm{a}} A_{\mathrm{c}}} \tanh (m H)}$

where

$m=\sqrt{\frac{h P}{K_{\mathrm{a}} A_{\mathrm{c}}}}$

$A_{\mathrm{c}}=L t$

$P=2(L+t)$

And $\mathrm{H}$ is the height of fin, $t$ is fin thickness of heat sink, $K_{\mathrm{a}}$ is the thermal conductivity of air.

Besides, the bulk of heat sink material's thermal resistance, $R_{\text {base }}$, is given by

$R_{\text {base }}=\frac{t_{\mathrm{b}}}{K L W}$ 
where $t_{\mathrm{b}}$ is the fins thickness of base plate, $\mathrm{K}$ is the thermal conductivity of heat sink. L, W are fin length and heat sink width, respectively.

The heat transfer coefficient of the plant-fin heat sink under natural convection is given by [21]:

$h=\frac{K_{\mathrm{a}}}{b}\left[\frac{576}{E I^{2}}+\frac{2.873}{E I^{0.5}}\right]^{-0.5}$

Here, EI is the Elenbaas number defined as

$E I=\frac{\rho^{2} \beta g C_{\mathrm{p}} b^{4} \bar{\theta}}{v_{\mathrm{f}} K_{\mathrm{a}} L}$

$\bar{\theta}$ is the average temperature difference between the heat sink and the ambient air, defined as

$\bar{\theta}=T_{1}-T_{2}$

And fin efficiency

$\eta=\frac{\tanh (m H)}{m H}$

To perform the thermal analysis for the plate-fin heat sink under free convection, the entropy generation rate as the objective function can be defined as follows

$\dot{S}_{\text {gen }}=f(n, t, H)=f\left(x_{\mathrm{i}}\right)$

where $\mathrm{n}$ is the number of fins, $\mathrm{t}$ is the thickness of fin, $\mathrm{H}$ is the height of the fin in meter, $\mathrm{T} 1$ is base temperature of the heat sink, and the $x_{\mathrm{i}}$ is the optimized variables in the object function.

In this study, the assumptions for the analysis as follows:

(1) No spreading or constriction resistance.

(2) Constant material thermo-physical of both air and solid.

(3) Adiabatic fin tips

(4) Uniform heat flux through entire base plate bottom surface.

\section{PARITICLE SWARM OPTIMIZATION (PSO)}

In 1995, Particle Swarm Optimization (PSO) developed by Kennedy and Eberhart [20] is an evolutionary computation technique for solving global optimization problems. It was inspired by the choreography of bird flocking and fish schooling. PSO is a simple algorithm as well as fast, highquality and effective. So it can be used in a wide variety of optimization problems. Each potential solution, called a particle, and each of them flies in the N-dimensional problem space with a velocity. In the simulation, each particle moves toward the optimum point based on its present velocity, its previous experience and the experience of its neighbors. The updates of the particles are calculated using the following equations.

$$
\begin{aligned}
& v(i,:)=w v(i,:)+c_{1} \operatorname{rand}_{1}(p b x(i,:)-p x(i,:)) \\
& +c_{2} \operatorname{rand}_{2}(g b x-p x(i,:))
\end{aligned}
$$

$p x(i,:)=p x(i,:)+v(i,:)$

where $i=1,2, \ldots ; i$ is the particle index; pbx denotes the best previous position that the corresponding particle has achieved; gbx represents the global best location; c1 and c2 are the acceleration factor, and ' $c 1$ ' as cognitive parameter represents the confidence the particle has in itself and ' $\mathrm{c} 2$ ' as social parameter represents the confidence the particle has in swarm; rand 1 and rand 2 are random numbers with a range of $[0,1]$; New position of particle is calculated by Eq.(17). In order to improve the convergence performance of PSO, Shi and Eberhart discussed the setting of inertia factor in several articles [22]. At present, the most commonly used is the linear decreasing weight (LDW) strategy proposed by Shi. The inertia weight ' $w$ ' is given by

$w=w_{\max }-\operatorname{iter}\left(w_{\max }-w_{\min }\right) /$ iter $r_{\max }$

where iter is the current number of iterations and $i t e r_{\text {max }}$ is the maximum number of iterations

\section{THE COMSTRAINT CONDITIONST}

The objective of function is the minimization of entropy generation rate considering linear and nonlinear inequality constraints as follow

$$
\begin{aligned}
& \min \dot{S}_{\text {gen }}=f(n, t, H)=f\left(x_{1}, x_{2}, x_{3}\right) \\
& \text { s.t. } \\
& g_{1}:(L-n t) /(n-1)-0.014 \leq 0 \\
& g_{2}: H(n-1) /(L-n t)-14 \leq 0 \\
& g_{3}: 1-H(n-1) /(L-n t) \leq 0 \\
& g_{4}: 20 \leq n \leq 28 \\
& g_{5}: 0.0006 \leq t \leq 0.0015 \\
& g_{6}: 0.035 \leq H \leq 0.045
\end{aligned}
$$

In the above constraints, $\mathrm{g} 1$ indicate that the fin gap should less than $1.4 \mathrm{~mm}$. And two constraints about g2 and $\mathrm{g} 3$ indicate that the ratio of the height and thickness of the fins should lie in the range between 1 and 14 due to limited space for installation. In addition to the above constraints, fin number as $\mathrm{g} 4$ showed should lie in the range between 20 and 28 , fin thickness as g5 showed should lie in the range between $0.6 \mathrm{~mm}$ and $1.5 \mathrm{~mm}$, fin height should lie in the range between $35 \mathrm{~mm}$ and $45 \mathrm{~mm}$. Equation (15) without considering constraint conditions, the right fitness function as shown below:

$$
\text { fitness }=\left\{\begin{array}{l}
\dot{S}_{\mathrm{gen}} \\
\dot{S}_{\mathrm{gen}}+\text { constant }
\end{array}\right.
$$

where 'constant' is set to 1000 as the penalty constant. The entropy production rate is equal to the fitness function when a solution meets the constraint about the structure size of the plate-fin heat sink. When a solution does not satisfy the restriction condition, the fitness function is equal to the sum of entropy production rate and the penalty constant. 
And the velocity of the particle on each dimension are confined to a maximum velocity $v_{i \max }$ as the Eq. (21) and (22) showed

$$
\begin{aligned}
& v_{i} \leq v_{\text {imax }} \\
& v_{\text {imax }}=c_{3}\left(p x_{\text {imax }}-p x_{\text {imin }}\right)
\end{aligned}
$$

where $v_{i \max }$ is the maximum allowed velocity of a particle in ith dimension. $p x_{i \min }$ and $p x_{i \max }$ are the minimum and maximum positions of the particles in ith dimension respectively. There, the value of $c_{3}$ is 0.2 .

\section{MAIN ALGORITHM}

The particle's best results and overall best solution were obtained using particle swarm optimizer by change each particle's velocity and position. The flowchart of PSO algorithm is shown in Figure 2.

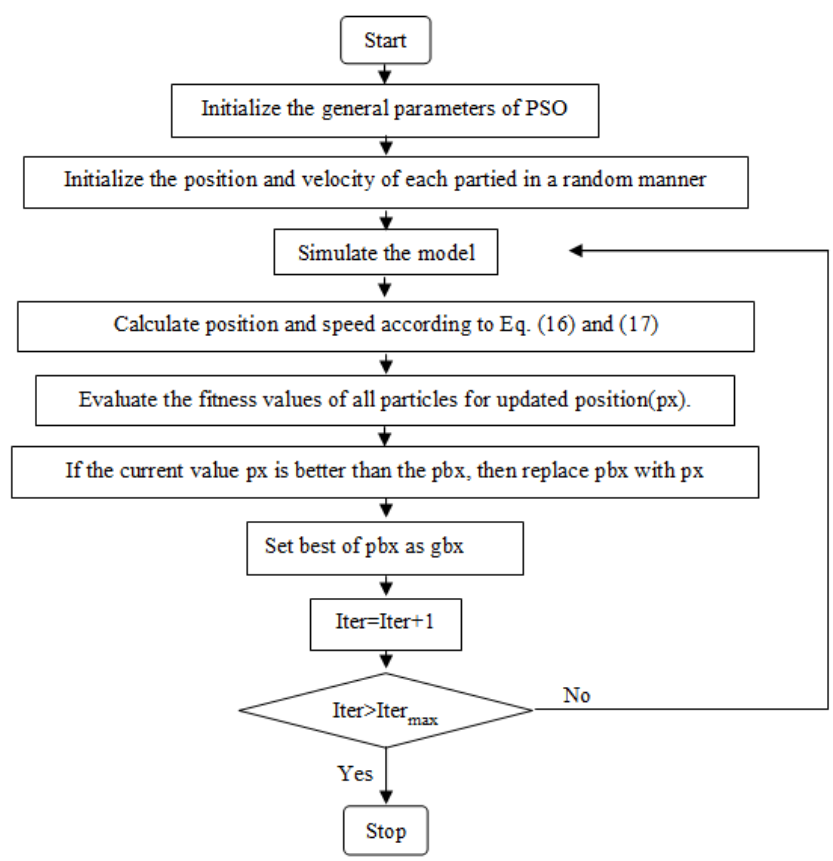

Figure 2. The flowchart of PSO algorithm

\section{THE RESULTS AND ANALYSIS}

The code for the PSO is written in MATLAB. After obtaining the optimum solution in the PSO approach, PSO algorithm is run 200 times by considering the following parameters: Number of particles (n) is 50; the acceleration factor $\mathrm{c} 1=\mathrm{c} 2=2$; the maximum velocity $\left(v_{\text {imax }}\right)$ of each dimension as shown in equation (21); the maximum number of generations ( iter $_{\max }$ ) is 200; the inertial weight (w) lie in the range between 0.4 and 0.9 ; Results are shown in Figure 3. After 200 iterations, it is interesting to observe that the lowermost entropy generation rate obtained is 0.002736 . And the optimal results are shown in Table 1: number of fin is 25 ; thickness of fin is $0.6 \mathrm{~mm}$; height of fin is $44.8 \mathrm{~mm}$.

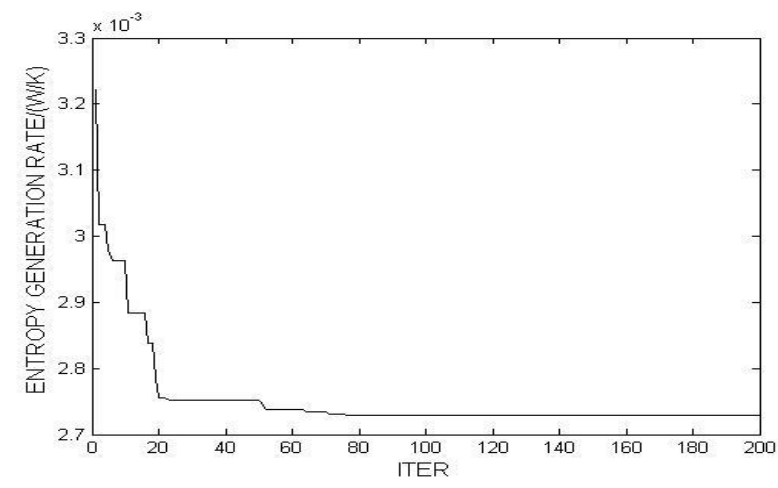

Figure 3. The convergence progress of PSO algorithm with respect to generation numbers

Table 1. Simulation result of plate fin heat sink

\begin{tabular}{llll}
\hline $\begin{array}{l}\text { Number of } \\
\text { fin }\end{array}$ & $\begin{array}{l}\text { Thickness of } \\
\text { fin [mm] }\end{array}$ & $\begin{array}{l}\text { Height of } \\
\text { fin [mm] }\end{array}$ & $\begin{array}{l}\text { Base } \\
\text { temperature }[\mathrm{k}]\end{array}$ \\
\hline 25 & 0.6 & 44.8 & 342.6241 \\
\hline
\end{tabular}

For the same model, we analyze the effect of fin number, fin height and fin thickness on entropy production rate. Figure 4 shows the entropy generation rate from a heat sink with respect to its different fin pitch while fin number is 25 , fin thickness is $0.6 \mathrm{~mm}$. With the increase of fin height, entropy production rate decreases and converge. But the material wastes more. In order to have a better economy and a good efficiency of heat sink, the height of fin should lie in the range between $42 \mathrm{~mm}$ and $50 \mathrm{~mm}$. Because in this range, the rate of entropy production rate decreases quickly and the material cost at a low level.

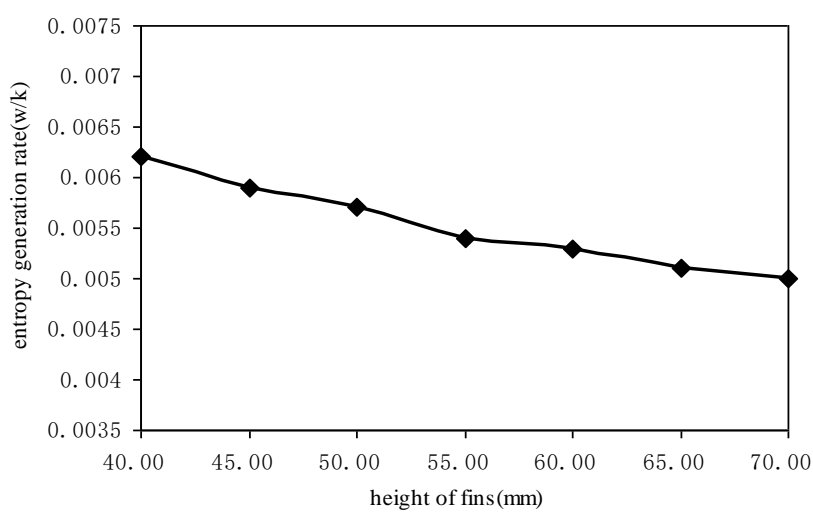

Figure 4. Entropy generation rate versus height of fins

Figure 5 shows a relationship between the entropy generation rate and the number of fins. Constraint conditions as follows: the height of fins is $44.8 \mathrm{~mm}$ and the thickness of fins is $0.6 \mathrm{~mm}$. Increasing the number of fins beyond the optimized value would lead to a decrease in the entropy generation rate. Because of the convection heat transfer area increased. Continue to increase the number of fin, the increase in the fluid drag associated with fin number results in an increase in the entropy generation rate. So the number of fin should lie in the range between 22 and 28. 


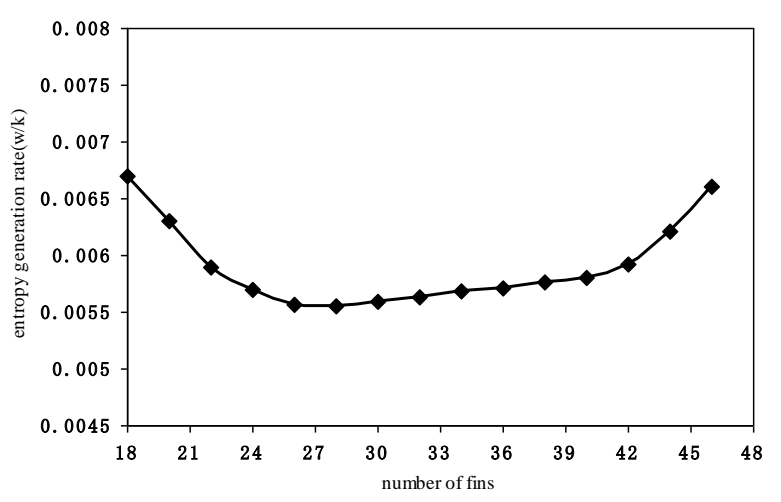

Figure 5. Entropy generation rate versus number of fins

Figure 6 shows a relationship between the entropy generation rate and the thickness of fins. Constraint conditions as follows: the height of fins is $44.8 \mathrm{~mm}$ and the number of fins is 25 . Increasing the thickness of fins beyond the optimized value would lead to a decrease in the entropy generation rate. And then, continue to increase the number of fin. Entropy generation rate would increase due to the increase of fluid drag. So, the thickness of fin should lie in the range between $0.5 \mathrm{~mm}$ and $1.5 \mathrm{~mm}$.

As we can see, the results of optimization, as shown in Table 1, inside the scope described above. At the same time, the order of influence on the entropy production rate is obtained according to the amount of reduction of entropy production rate: $\mathrm{t}>\mathrm{n}>\mathrm{H}$.

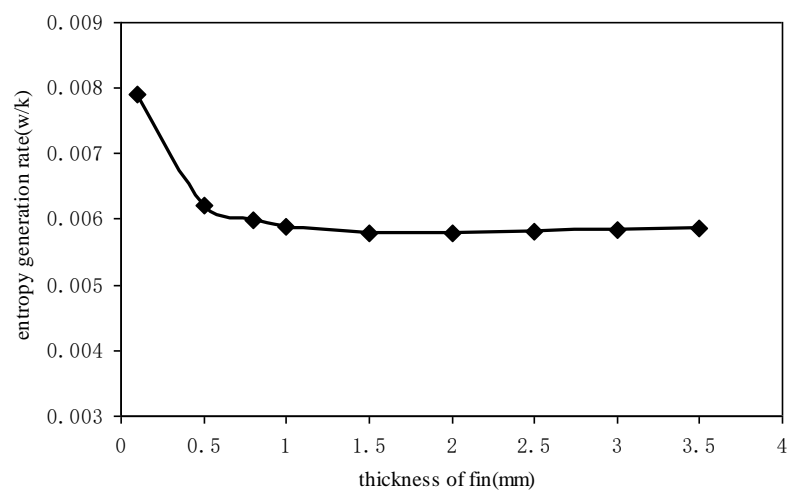

Figure 6. Entropy generation rate versus thickness of fins

\section{CONCLUSIONS}

The minimization of entropy generation rate as objective function is widely used on the thermodynamic optimization of plant-fin heat sink. But there is no literature reported using the particle swarm algorithm to optimize the plant-fin heat sink under natural convection. There, we established the mathematical model about a relationship between the entropy production rate and heat sink design parameters. Three design parameters as optimization variables are fin number, fin thickness and fin height. Then, we use particle swarm optimization algorithm to design the plate-fin heat sink considering the minimization of entropy generation. In this study, the constraints of the object function in particle swarm optimization (PSO) algorithm use constant penalty function method. Then, the optimal design parameters can be gained as Table1 showed: number of fin is 25 ; thickness of fin is
$0.6 \mathrm{~mm}$; height of fin is $44.8 \mathrm{~mm}$ and the corresponding temperature of the base plant is $342.6241 \mathrm{k}$. The lowermost entropy generation rate obtained is $0.002736 \mathrm{w} / \mathrm{k}$. Furthermore, the effect of design variables on entropy generation rate is also presented as shown in Figure 4 to Figure 6. And we can find the most important factor affecting entropy production rate is the thickness of fin. At the same time, the present study demonstrates the particle swarm algorithm can provide a strong ability of auto-search and few in parameters in the optimization design of heat sink. And, in this paper, PSO is applied to the optimization design of the plant-fin heat sink, which can be extended to other types of heat sink. For other types of heat sink optimization, we need to do is according to different design conditions and requirements to choose the optimization objectives, constrains and optimization variables. Then based on the PSO algorithm can get the optimization results.

\section{ACKNOWLEDGMENT}

This project is jointly supported by the National Natural Science Foundation of China, No. 51566002, and by Guangxi Key Lab of Unmanned Aerial Vehicle Telemetry, No. 201550625, by Innovation Project of GUET Graduate Education, No.2016YJCX96.

\section{REFERENCES}

[1] A. Bar-Cohen, "Thermal packaging for the 21st century: Challenges and options," presented at 5th International Workshop on Thermal Investigations of ICs and Microstructures, Rome, Italy, Oct. 3-6, 1999.

[2] M. A. Ben and A. Bar-Cohen, "Heat sink optimization for maximum performance and minimum mass," in Proc. InterPACK'99 Conf, Hawaii, USA, 1999, pp. 734-744.

[3] Chyi-Tsong Chen and Hung-I. Chen, "Multi-objective optimization design of plate-fin heat sinks using a direction-based genetic algorithm," Journal of the Taiwan Institute of Chemical Engineers, vol. 44, no. 2, pp. 257-265, 2013. DOI: 10.1016/j.jtice.2012.11.012.

[4] F. P. Incropera, "Convection heat transfer in electronic equipment cooling," J. Heat Transfer, vol. 110, no. 110, pp. 1097-1111, 1998. DOI: 10.1115/1.3250613.

[5] W. Nakayama, "Thermal Management of Electronic Equipment: a Review of Technology and Research Topics," Applied Mechanics Reviews, vol. 39, no. 12, pp. 1847-1868, 1986. DOI: 10.1115/1.3149515.

[6] Liang Caihang, He Zhuang, Yang Yongwang and Zeng $\mathrm{Si}$, "Experimental study on thermal performance of pulsating heat pipe with ethanol-acetone mixtures," International Journal of Heat \& Technology, vol. 33, no. 4, pp. 185-190, 2015. DOI: 10.18280/ijht.330424.

[7] M. B. Dogruoz, "Experiments and modeling of the hydraulic resistance and heat transfer of in-line square pin fin heat sinks with top by-pass flow," International Journal of Heat and Mass Transfer, vol. 48, no. 23, pp. 5058-5071, 2005. DOI: $10.1016 /$ j.ijheatmass trans fer.2005.07.004.

[8] K. Yakut, "Experimental investigation of thermal resistance of a heat sink with hexagonal fins," Applied Thermal Engineering, vol. 26, no. 17, pp. 2262-2271, 2006. DOI: 10.1016/j.applthermaleng.2006.03.008. 
[9] J. S. Issa and A. Ortega, "Experimental measurements of the flow and heat transfer of a square jet impinging on an array of square pin fins," Journal of Electronic Packaging, vol. 128, no. 1, pp. 61-70, 2006. DOI: 10 . $1115 / 1.2160513$.

[10] A. Bejan, "Entropy generation through heat and fluid flow," Journal of Applied Mechanics, vol. 50, no. 2 , pp. 475-478, 1983. DOI: $10.1115 / 1.3167072$.

[11] A. Bejan, "Entropy generation minimization-the new thermodynamics of finite-size devices and finite-time processes," Journal of Applied Physics, vol. 79, no. 3, pp. 1191-1218, 1996. DOI: $10.1063 / 1.362674$.

[12] J. R. Culham and Y. S. Muzychka, "Optimization of plate-fin heat sink using entropy generation minimization," IEEE Transactions on Components and Packaging Technologies, vol. 24, pp. 159-165, 2001. DOI: $10.1109 / 6144.926378$.

[13] C. J. Shih and G. C. Liu, "Optimal design methodology of plate-fin heat sinks for electronic cooling system using entropy generation strategy," IEEE Transactions on Components and Packaging Technologies, vol. 27, no. 3, pp. 551-559, 2004. DOI: 10.1109/TCAPT.200 4.831812.

[14] M. Iyengar and A. Bar-Cohen, "Least-energy optimization of forced convection plate-fin heat sinks," IEEE Transactions on Components and Packaging Technologies, vol. 26, no. 1, pp. 62-70, 2003. DOI: 10.1109/TCAPT.2003.811484.

[15] C. T. Chen, C. K. Wu and C. Hwang, "Optimal design and control of CPU heat sink processes," IEEE Transactions on Components and Packaging Technologies, vol. 31, no. 1, pp. 184-195, 2008. DOI: 10.1109/TCAPT.2008.916855.

[16] O. O. Adewumi, T. Bello-Ochende and J. P. Meyer, "Constructal design of single microchannel heat sink with varying axial length and temperature-dependent fluid properties," International Journal of Heat \& Technology, vol. 34, no. 1, pp. 167-172, 2016. DOI: 10.1828 0/ijht.34S122.

[17] R. V. Rao and G. G. Waghmare, "Multi-Objective design optimization of a plate-fin heat sink using a teaching-learning-based optimization algorithm," Applied Thermal Engineering, vol. 76, pp. 521-529, 2015. DOI: 10. 1016/j. applthermaleng. 2014. 11. 052.

[18] Mustapha Faraji and Hamid El Qarnia, "Numerical optimization of a thermal performance of a phase change material based heat sink," International Journal of Heat \& Technology, vol. 26, no. 2, pp. 17 24, 2008.

[19] K. T. Chiang, F. P. Chang and T. C. Tsai, "Optimum design parameter of pin-fin heat sink using the greyfuzzy logic based on the orthogonal arrays," International Communications in Heat and Mass Transfer, vol. 33, no. 6, pp. 744-752, 2006. DOI: 10. 1016/j. icheatmass transfer. 2006. 02.011.

[20] J. Kennedy and R. Berhart. "Particle swarm optimization," Proceedings of IEEE International Conference on Neural Networks, vol. 4, no. 8, pp. 1942-1948, 1995. DOI: 10.1109/ICNN. 1995. 488968.

[21] W. Elenbaas, "Heat dissipation of parallel plates by free convection," Physica, vol. 9, no. 1, pp. 1-28, 1942. DOI: $10.1016 / \mathrm{S} 0031-8914(42) 90053-3$.

[22] Y. Shi, R. Eberhart, "Modified particle swarm optimizer," in IEEE World Congress on
Computational Intelligence, 1998, pp. 69-73. DOI: 10. 1109/ICEC. 1998. 699146.

\section{NOMENCLATURE}

\begin{tabular}{|c|c|}
\hline$A_{c}$ & cross section area of fin, $\mathrm{m}^{2}$ \\
\hline $\mathrm{b}$ & spacing between two fins, $m$ \\
\hline $\mathrm{c}_{1}, \mathrm{c}_{2}$ & acceleration parameter (for PSO algorithm) \\
\hline constant & Penalty constant \\
\hline $\mathrm{C}_{\mathrm{p}}$ & specific heat, $\mathrm{J} / \mathrm{kg} \mathrm{K}$ \\
\hline EI & Elenbaas number \\
\hline $\mathrm{g}$ & acceleration of gravity, $\mathrm{m} / \mathrm{s}^{2}$ \\
\hline $\mathrm{g}_{\mathrm{i}}$ & constraint \\
\hline $\mathrm{H}$ & height of fin, $m$ \\
\hline $\mathrm{h}$ & heat transfer coefficient, $\mathrm{W} / \mathrm{m}^{2} \mathrm{~K}$ \\
\hline K & thermal conductivity of heat sink, W/m K \\
\hline $\mathrm{K}_{\mathrm{a}}$ & thermal conductivity of air, $\mathrm{W} / \mathrm{m} \mathrm{K}$ \\
\hline $\mathrm{L}$ & heat sink length, $\mathrm{m}$ \\
\hline $\mathrm{m}$ & fin parameter $\approx \sqrt{h P / K_{a} A_{c}}, \mathrm{~m}^{-1}$ \\
\hline $\mathrm{n}$ & fin number \\
\hline $\mathrm{P}$ & cross section circumference of the fin, $m$ \\
\hline $\mathrm{px}$ & particle's position (for PSO algorithm) \\
\hline Q & heat load, W \\
\hline$R_{\text {base }}$ & $\begin{array}{l}\text { the thermal resistance of the bulk material, } \\
\mathrm{K} / \mathrm{W}\end{array}$ \\
\hline $\mathrm{R}_{\text {sink }}$ & $\begin{array}{l}\text { the overall thermal resistance of the heat } \\
\text { sink, K/W }\end{array}$ \\
\hline $\mathrm{R}_{\text {total }}$ & the overall thermal resistance of fins, $\mathrm{K} / \mathrm{W}$ \\
\hline $\mathrm{R}_{\text {fin }}$ & thermal resistance of each fin, $\mathrm{K} / \mathrm{W}$ \\
\hline$\dot{S}_{g e n}$ & entropy generation rate, $\mathrm{W} / \mathrm{K}$ \\
\hline $\mathrm{T}_{1}$ & base temperature, $\mathrm{K}$ \\
\hline $\mathrm{T}_{2}$ & ambient temperature, $\mathrm{K}$ \\
\hline $\mathrm{t}$ & thickness of fin, $m$ \\
\hline$t_{b}$ & base plate thickness, $\mathrm{m}$ \\
\hline $\mathrm{v}$ & particle velocity (for PSO algorithm) \\
\hline $\mathrm{W}$ & inertia weight (for PSO algorithm) \\
\hline $\mathrm{W}$ & width of the plate-fin, $m$ \\
\hline $\mathrm{X}_{\mathrm{i}}$ & design variables \\
\hline
\end{tabular}

\section{Greek letters}

$\beta \quad$ thermal expansion coefficient

$\rho \quad$ density of air, $\mathrm{kg} / \mathrm{m}^{3}$

$\eta \quad$ fin efficiency

$\bar{\theta} \quad$ average temperature difference between heat sink and ambient air, $\mathrm{k}$

$\theta_{\mathrm{b}} \quad$ temperature excess of the heat sink base plate, $\mathrm{k}$

\section{Subscripts}

$\begin{array}{ll}\text { a } & \text { air } \\ \mathrm{b} & \text { base plate } \\ \text { fin } & \text { single fin } \\ \mathrm{i} & \text { particle index(for PSO algorithm) } \\ \text { gen } & \text { generation } \\ \max & \text { maximum } \\ \min & \text { minimum } \\ \text { sink } & \text { heat sink }\end{array}$

